\title{
Coronary Artery Bypass Surgery in Brazil: Analysis of the National Reality Through the BYPASS Registry
}

Rodrigo Pereira Paez ${ }^{1}$, MD; Nelson Américo Hossne Junior ${ }^{1}$, MD, MSc; José Amalth do Espírito Santo ${ }^{2}$, MD; Otavio Berwanger ${ }^{2}, \mathrm{MD}, \mathrm{PhD}$; Renato Hideo Nakagawa Santos ${ }^{2}$, MD; Renato Abdala Karam Kalil ${ }^{3}, \mathrm{MD}, \mathrm{MSc}$, PhD; Fabio B. Jatene ${ }^{4}, \mathrm{MD}, \mathrm{PhD}$; Alexandre Biasi Cavalcanti², MD, PhD; Alexandre Cabral Zilli5, MD; Luiz Carlos Bettiati Jr ${ }^{5}$, MD; Fernando Augusto Marinho dos Santos Figueira ${ }^{6}$, MD; Stephanie Steremberg Pires D'Azevedo ${ }^{6}$, RN; Marcelo José Ferreira Soares ${ }^{7}$, MD; Marcio Pimentel Fernandes ${ }^{7}, \mathrm{MD}$; Roberto Vito Ardito ${ }^{8}$, MD; Renata Andrea Barberio Bogdan $^{8}$, MD; Valquíria Pelisser Campagnucci ${ }^{9}$, MD, MSc, PhD; Diana Nakasako ${ }^{9}$, MD; Clarissa Garcia Rodrigues ${ }^{3}$, RN, MSc, PhD; Anilton Bezerra Rodrigues Junior ${ }^{10}$, MD; Marcelo Matos Cascudo ${ }^{10}$, MD; Fernando Antibas Atik ${ }^{11}$, MD, PhD; Elson Borges Lima ${ }^{11}$, MD; Vinicius José da Silva Nina ${ }^{12}$, MD, PhD; Renato Albuquerque Heluy ${ }^{12}$; Lisandro Gonçalves Azeredo ${ }^{13}$, MD; Odilon Silva Henrique Junior ${ }^{13}$, MD; José Teles de Mendonça ${ }^{14}$, MD, PhD; Katharina

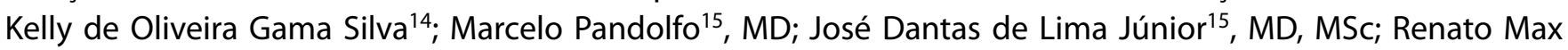
Faria ${ }^{16}, \mathrm{MD}$; Jonas Gonçalves dos Santos ${ }^{16}$, MD; Guilherme Henrique Biachi Coelho ${ }^{17}$, MD; Sergio Nunes Pereira ${ }^{18}$, MD; Roberta Senger ${ }^{18}$, RN; Enio Buffolo ${ }^{19}$, MD, PhD; Guido Marco Caputi ${ }^{19}$, MD, PhD; Juliana Aparecida Borges de Oliveira ${ }^{2}$, RN; Walter J. Gomes ${ }^{1}$, MD, MSc, PhD; and the BYPASS Registry Study Group

${ }^{1}$ Hospital São Paulo, Escola Paulista de Medicina da Universidade Federal de São Paulo, (EPM - UNIFESP), São Paulo, SP, Brazil.

${ }^{2}$ Instituto de Pesquisa do Hospital do Coração (IP - HCor), São Paulo, SP, Brazil. IInstituto de Cardiologia do Rio Grande do Sul - Fundação Universitária de Cardiologia, Porto Alegre, RS, Brazil.

${ }^{4}$ Cardiovascular Surgery Division, Instituto do Coração do Hospital das Clínicas da Faculdade de Medicina da Universidade de São Paulo (InCor-HCFMUSP), São Paulo, SP, Brazil.

${ }^{5}$ Hospital de Caridade São Vicente de Paulo, Jundiaí, SP, Brazil.

${ }^{6}$ Instituto de Medicina Integral Professor Fernando Figueira (IMIP), Recife, PE, Brazil.

${ }^{7}$ Hospital de Base - FUNFARME e FAMERP, São José do Rio Preto, SP, Brazil. ${ }^{8}$ Instituto de Moléstias Cardiovasculares (IMC), São José do Rio Preto, SP, Brazil.

${ }^{9}$ Irmandade da Santa Casa de São Paulo (INCT-HPV/Faculdade de Ciências Médicas da Santa Casa de São Paulo), São Paulo, SP, Brazil

${ }^{10}$ Instituto do Coração de Natal, Natal, RN, Brazil.

${ }^{11}$ Instituto de Cardiologia do Distrito Federal, Brasília, DF, Brazil.

${ }^{12}$ Hospital Universitário da Universidade Federal do Maranhão (HU/UFMA), São Luís, MA, Brazil.
${ }^{3}$ Hospital Evangélico, Cachoeiro de Itapemirim, ES, Brazil.

${ }^{14}$ Hospital do Coração de Sergipe, Aracaju, SE, Brazil.

${ }^{15}$ Instituto de Cirurgia Cardiovascular (ICCV)/Hospital Nossa Senhora da Salete, Cascavel, PR, Brazil.

${ }^{16}$ Hospital Wilson Rosado, Mossoró, RN, Brazil.

${ }^{17}$ Hospital Bosque da Saúde, São Paulo, SP, Brazil.

${ }^{18}$ Hospital Universitário de Santa Maria, Santa Maria, RS, Brazil.

${ }^{19}$ Hospital do Coração (HCor), São Paulo, SP, Brazil.

This study was carried out at the Universidade Federal de São Paulo (UNIFESP) EPM), São Paulo, SP, Brazil.

Correspondence Address:

Rodrigo Pereira Paez

(iD) https://orcid.org/0000-0001-5860-901X

Avenida Iraí, 2104 - São Paulo, SP, Brazil - Zip code: 04082-006

E-mail: rppaez@me.com 


\section{Abstract}

Introduction: Coronary artery bypass grafting (CABG) is the most frequently performed heart surgery in Brazil. Recent international guidelines recommend that national societies establish a database on the practice and results of CABG. In anticipation of the recommendation, the BYPASS Registry was introduced in 2015.

Objective: To analyze the profile, risk factors and outcomes of patients undergoing CABG in Brazil, as well as to examine the predominant surgical strategy, based on the data included in the BYPASS Registry.

Methods: A cross-sectional study of 2292 patients undergoing CABG surgery and cataloged in the BYPASS Registry up to November 2018. Demographic data, clinical presentation, operative variables, and postoperative hospital outcomes were analyzed.

Results: Patients referred to CABG in Brazil are predominantly male $(71 \%)$, with prior myocardial infarction in $41.1 \%$ of cases, diabetes in $42.5 \%$, and ejection fraction lower than $40 \%$ in $9.7 \%$. The Heart Team indicated surgery in $32.9 \%$ of the cases. Most of the patients underwent cardiopulmonary bypass (87\%), and cardioplegia was the strategy of myocardial protection chosen in $95.2 \%$ of the cases. The left internal thoracic artery was used as a graft in $\mathbf{9 1 \%}$ of the cases; the right internal thoracic artery, in $5.6 \%$; and the radial artery in $1.1 \%$. The saphenous vein graft was used in $84.1 \%$ of the patients, being the only graft employed in $7.7 \%$ of the patients. The median number of coronary vessels treated was 3. Operative mortality was $2.8 \%$, and the incidence of cerebrovascular accident was $1.2 \%$.

Conclusion: CABG data in Brazil provided by the BYPASS Registry analysis are representative of our national reality and practice. This database constitutes an important reference for indications and comparisons of therapeutic procedures, as well as to propose subsequent models to improve patient safety and the quality of surgical practice in the country.

Keywords: Registries. Database, Cardiovascular Surgical Procedures. Cardiac Surgical Procedures. Coronary Artery Bypass Grafts. Myocardial Revascularization.

\begin{tabular}{|c|c|c|c|}
\hline \multicolumn{4}{|c|}{ Abbreviations, acronyms \& symbols } \\
\hline ADA & $=$ Anterior descending artery & GCP & $=$ Good Clinical Practices \\
\hline ARDS & $=$ Adult respiratory distress syndrome & ITA & $=$ Internal thoracic artery \\
\hline \multirow[t]{2}{*}{ BYPASS } & $=$ Brazilian Registry of Adult Patients Undergoing & LAD & $=$ Left anterior descending \\
\hline & Cardiovascular Surgery & LITA & $=$ Left internal thoracic artery \\
\hline CABG & $=$ Coronary artery bypass grafting & LVEF & $=$ Left ventricular ejection fraction \\
\hline CAD & $=$ Coronary artery disease & MI & = Myocardial infarction \\
\hline COPD & $=$ Chronic obstructive pulmonary disease & NYHA & $=$ New York Heart Association classification for heart \\
\hline CPB & $=$ Cardiopulmonary bypass & & failure \\
\hline EACTS & = European Association for Cardio-Thoracic Surgery & $\mathrm{PCl}$ & $=$ Percutaneous coronary intervention \\
\hline \multirow[t]{2}{*}{ EAPCI } & = European Association of Percutaneous Cardiovascular & RITA & $=$ Right internal thoracic artery \\
\hline & Interventions & SBCCV & $=$ Sociedade Brasileira de Cirurgia Cardiovascular \\
\hline ESC & = European Society of Cardiology & STS & = Society of Thoracic Surgeons \\
\hline \multirow{2}{*}{\multicolumn{2}{|c|}{$\begin{aligned} \text { FREEDOM }= & \text { Future Revascularization Evaluation in Patients with } \\
& \text { Diabetes Mellitus: Optimal Management of Multivessel } \\
& \text { Disease }\end{aligned}$}} & SVG & $=$ Saphenous vein grafts \\
\hline & & SYNTAX & $\begin{aligned}= & \text { Synergy Between Percutaneous Coronary Intervention } \\
& \text { with TAXUS and Cardiac Surgery }\end{aligned}$ \\
\hline
\end{tabular}

\section{INTRODUCTION}

The Brazilian Registry of Adult Patients Undergoing Cardiovascular Surgery - the BYPASS Project - is an ongoing database established in 2015 by the Sociedade Brasileira de Cirurgia Cardiovascular (SBCCV) and aimed to collect perioperative and postoperative data from patients undergoing cardiac surgery in Brazil.

The first report of the BYPASS revealed that coronary artery bypass grafting (CABG) is the most frequently performed cardiac surgery in Brazil, encompassing $54.1 \%$ of the cases $^{[1]}$. CABG remains the standard of care for management of patients with coronary artery disease, particularly in high-risk patients with multivessel disease, diabetics, aged 65 years or more, with left main stem or with impaired left ventricular function.

Previous analyses of results of CABG patients in Brazil were derived from single centers, a group of hospitals or defective databases, failing to reach national representativeness. Recent international guidelines recommend that national societies establish their own database on the practice and results of CABG and, in anticipation of this, the BYPASS registry was introduced in $2015^{[2,3]}$.

To provide a comprehensive understanding of the scenario of cardiovascular surgery in Brazil, this analysis presents the clinical profile and outcomes of patients undergoing CABG and enrolled in the BYPASS project, assessing the data harvested from the initial cohort of patients included.

\section{METHODS}

This study was approved by the Research Ethics Committee of the Universidade Federal de São Paulo (UNIFESP - Registration number 1143/2017) and compiled data from the Bypass Registry, an observational and prospective study, with longitudinal followup. This report comprises a cross-sectional study, evaluating patients undergoing first-time isolated CABG. 


\section{Population and Locations}

The participation of cardiovascular centers in this project was voluntary and involved 17 institutions throughout the country and located in the following regions: Southeast ${ }^{[4]}$, Northeast ${ }^{[5]}$, South ${ }^{[3]}$, and Central-West ${ }^{[1]}$.

The project is partnered with the HCor Research Institute, responsible for collecting, analyzing and auditing the data.

A total of 2292 patients were analyzed, included until November 2018. The population consisted of patients older than 18 years of age, submitted to first-time isolated $C A B G$, without other associated procedures. The informed consent form was signed by every patient included in the study and the data collection followed the National Clinical Research regulation standards as well as the Document of the Americas and Good Clinical Practice (GCP). The Bypass Registry was approved by the Ethics and Research Committee of the coordinating center and each participating institution.

\section{Profile and Outcomes}

The main variables assessed were demographic data, clinical presentation, risk factors, medications in use, left ventricular ejection fraction (LVEF), evaluated by echocardiography, and laboratory tests. Intraoperative data recorded operative time, use of cardiopulmonary bypass (CPB) and cardioplegia, type of grafts harvested, and preferred anastomotic techniques (direct, sequential or Y-composite grafts). Postoperative data included incidence of the following complications: stroke, major bleeding requiring reoperation, utilization of blood products, vasoplegia, arrhythmia, myocardial infarction, low cardiac output, use of vasoactive drugs, mechanical ventilation longer than 24 hours, kidney failure, need for transfusion, infection, and hospital mortality.

\section{Statistical Analysis}

The quantitative variables were described by mean \pm standard deviation, and the qualitative variables were presented in form of absolute and relative frequency. Statistical analyses were performed with the Statistical Package $\mathrm{R}$ version 3.3.2 ( $\mathrm{R}$ Foundation for Statistical Computing).

\section{RESULTS}

Epidemiological data and relative risk factors for heart disease are presented in Table 1. Patients referred to CABG in Brazil were predominantly male $(71 \%)$, mean age $63.5 \pm 9.6$ years, with recent myocardial infarction (MI) in $41.1 \%$ of the cases.

Table 2 depicts the reimbursement source, whether public or private, and the setting in which the patients were operated on; i.e., elective or urgent surgery. Most of the patients were admitted through the public healthcare system (84.4\%) and operated under elective conditions (77.7\%).

Intraoperative variables regarding surgical access, use of cardiopulmonary bypass, myocardial protection, use of internal thoracic artery and other arterial grafts, Y- or sequential grafts were collected according to Table 3.

Intraoperative clinical events, such as bleeding, vasoplegia,
Table 1. Demographics data.

\begin{tabular}{|c|c|}
\hline & Total $(n=2292)$ \\
\hline Sex (female) & $665 / 2292$ (29\%) \\
\hline Age; mean $\pm S D$ (years) & $63.5 \pm 9.6$ \\
\hline Family history & 867/2292 (37.8\%) \\
\hline Diabetes & 973/2292 (42.5\%) \\
\hline Dyslipidemia & $1250 / 2292(54.5 \%)$ \\
\hline Hypertension & 1937/2292 (84.5\%) \\
\hline Infarction & 941/2292 (41.1\%) \\
\hline Previous PCl & 289/2292 (12.6\%) \\
\hline Previous heart surgery & 48/2292 (2.1\%) \\
\hline CVA & $93 / 2292(4.1 \%)$ \\
\hline PAD & 170/2292 (7.4\%) \\
\hline Heart failure & 328/2292 (14.3\%) \\
\hline NYHA (1) & 42/312 (13.5\%) \\
\hline NYHA (2) & 181/312 (58\%) \\
\hline NYHA (3) & $82 / 312(26.3 \%)$ \\
\hline NYHA (4) & 7/312 (2.2\%) \\
\hline Kidney failure & $111 / 2292(4.8 \%)$ \\
\hline Dialysis & 18/109 (16.5\%) \\
\hline Cardiac arrest & 45/2292 (2\%) \\
\hline Current smoker & 309/2292 (13.5\%) \\
\hline Ex-smoker & $570 / 2286$ (24.9\%) \\
\hline Arrhythmia & 117/2292 (5.1\%) \\
\hline Pacemaker & 20/2292 (0.9\%) \\
\hline COPD & 128/2292 (5.6\%) \\
\hline$E F<40 \%$ & 185/1904 (9.7\%) \\
\hline
\end{tabular}

$\mathrm{COPD}=$ chronic obstructive pulmonary disease; $\mathrm{CVA}=$ cerebrovascular accident; $E F=$ ejection fraction; NYHA=New York Heart Association classification for heart failure; PAD=peripheral artery disease; $\mathrm{PCl}=$ percutaneous coronary intervention

arrhythmias, infarction [defined as an elevation of more than 10 times the upper limit of troponin T], use of vasopressors and intraoperative death are shown in Table 4. Postoperative follow-up was also analyzed in view of the main indicators and complications that may occur, according to Table 5.

Most of the patients underwent CPB (87\%), and cardioplegia was the strategy of myocardial protection chosen in $95.2 \%$ of the cases.

The left internal thoracic artery (LITA) was used in $91 \%$ of the cases; the right internal thoracic artery (RITA), in 5.6\%; and radial 
Table 2. Reimbursement source and preoperative conditions.

\begin{tabular}{l|c}
\hline & Total (n=2292) \\
\hline Reimbursement source & \\
\hline Public healthcare system & $1934 / 2292(84.4 \%)$ \\
\hline Private - Health insurance & $358 / 2292(15.7 \%)$ \\
\hline Type of procedure & \\
\hline Elective surgery & $1781 / 2292(77.7 \%)$ \\
\hline Urgent surgery & $478 / 2292(20.9 \%)$ \\
\hline Emergency surgery & $32 / 2292(1.4 \%)$ \\
\hline Surgery indicated by the Heart Team & $754 / 2292(32.9 \%)$ \\
\hline Clinical conditions & \\
\hline Stable & $2212 / 2292(96.5 \%)$ \\
\hline Unstable & $73 / 2292(3.2 \%)$ \\
\hline Critical & $7 / 2292(0.3 \%)$ \\
\hline
\end{tabular}

Table 3. Intraoperative characteristics.

\begin{tabular}{|c|c|}
\hline & Total $(n=2292)$ \\
\hline Open-heart surgery & $2291 / 2292(100 \%)$ \\
\hline Minimally invasive surgery & 1/2292 (0\%) \\
\hline Use of cardiopulmonary bypass & 1994/2292 (87\%) \\
\hline Cardioplegia & 1899/1994 (95.2\%) \\
\hline \multicolumn{2}{|l|}{ Grafts } \\
\hline SVG & 1925/2289 (84.1\%) \\
\hline No SVG (only arterial grafts) & $364 / 2289(15.9 \%)$ \\
\hline Only SVG & $176 / 2289(7.7 \%)$ \\
\hline Use of LITA & $2083 / 2289(91 \%)$ \\
\hline Use of RITA & $129 / 2289(5.6 \%)$ \\
\hline \multicolumn{2}{|l|}{ One ITA } \\
\hline Use of LITA or RITA & 1994/2289 (87.1\%) \\
\hline Use of Only LITA or RITA & $300 / 2289(13.1 \%)$ \\
\hline \multicolumn{2}{|l|}{ Two ITA } \\
\hline Use of LITA and RITA & 109/2289 (4.8\%) \\
\hline Use of Only LITA and RITA & $48 / 2289(2.1 \%)$ \\
\hline Use of radial artery & $25 / 2289(1.1 \%)$ \\
\hline Treated vessels; median [quartiles] & $3[2-4](n=2292)$ \\
\hline
\end{tabular}

Table 4. Intraoperative complications.

\begin{tabular}{l|c}
\hline & Total (n=2292) \\
\hline Myocardial infarction & $11 / 2292(0.5 \%)$ \\
\hline Major bleeding & $119 / 2292(5.2 \%)$ \\
\hline Transfusion & $539 / 2292(23.5 \%)$ \\
\hline Postperfusion syndrome & $15 / 2292(0.7 \%)$ \\
\hline Arrhythmia & $70 / 2292(3.1 \%)$ \\
\hline Low cardiac output & $102 / 2292(4.5 \%)$ \\
\hline Use of vasoconstrictors & $1137 / 2292(49.6 \%)$ \\
\hline Intraoperative death & $12 / 2292(0.5 \%)$ \\
\hline
\end{tabular}

Table 5. Postoperative intra-hospital data.

\begin{tabular}{|c|c|}
\hline & Total $(n=2292)$ \\
\hline Reoperation & $52 / 2280(2.3 \%)$ \\
\hline Major bleeding & $62 / 2280(2.7 \%)$ \\
\hline $\mathrm{PCl}$ & $5 / 2280(0.2 \%)$ \\
\hline $\begin{array}{l}\text { Mechanical ventilation more } \\
\text { than } 24 \mathrm{~h}\end{array}$ & $120 / 2280(5.3 \%)$ \\
\hline Tracheostomy & $12 / 2280(0.5 \%)$ \\
\hline ARDS & $33 / 2280(1.4 \%)$ \\
\hline Low cardiac output & $73 / 2280(3.2 \%)$ \\
\hline Kidney failure & $84 / 2280(3.7 \%)$ \\
\hline Dialysis & $30 / 84(35.7 \%)$ \\
\hline Coagulopathy & $23 / 2280(1 \%)$ \\
\hline Transfusion & $446 / 2280(19.6 \%)$ \\
\hline Arrythmias & $336 / 2280(14.7 \%)$ \\
\hline Need for pacemaker & $91 / 2280(4 \%)$ \\
\hline Infection & $118 / 2280(5.2 \%)$ \\
\hline Myocardial infarction & $27 / 2280(1.2 \%)$ \\
\hline Vasoplegic syndrome & $27 / 2280(1.2 \%)$ \\
\hline Death & $64 / 2292(2.8 \%)$ \\
\hline Heart failure & $29 / 2280(1.3 \%)$ \\
\hline CVA & $28 / 2280(1.2 \%)$ \\
\hline
\end{tabular}

ARDS=adult respiratory distress syndrome; $C V A=$ cardiovascular accident; $\mathrm{PCl}=$ percutaneous coronary intervention 
artery in only $1.1 \%$. Total arterial revascularization was performed in $15.9 \%$, and a significant portion (13.1\%, 300 of 2289 patients) received an isolated internal thoracic artery graft to the left anterior descending (LAD) artery.

Saphenous vein grafts (SVG) were used in up to $84.1 \%$ of patients. There were $7.7 \%$ of patients revascularized with vein grafts only, without arterial grafts. The median number of vessels treated was $3^{[2,3]}$.

The in-hospital mortality rate was $2.8 \%$, and the incidence of clinically relevant cerebrovascular accident was 1.2\%.

\section{DISCUSSION}

Coronary artery disease is one of the leading causes of mortality and morbidity in the $21^{\text {st }}$ century ${ }^{[4]}$. In Brazil, approximately $30 \%$ of people die from cardiovascular causes according to data from the Unified Health System (DATASUS) ${ }^{[5]}$.

In 2014, CABG celebrated six decades since Kolesov's direct coronary approach for myocardial revascularization. And the technique continues to evolve at all times, from the onset of the worldwide experience without $C P B$, to the advent of $C P B$, returning to new scenarios without the use of $\mathrm{CPB}^{[6]}$; from the use of the saphenous vein to the use of the internal thoracic artery, including sequential anastomoses, until coronary artery bypass grafting completely performed with arterial grafts ${ }^{[7]}$, with graft quality control by Doppler graft flow measurement ${ }^{[4]}$.

In patients with stable chronic disease, CABG is indicated to relieve symptoms and/or improve prognosis ${ }^{[8]}$. CABG surgery has well established indications and benefits when it comes to left main artery disease, multivessel coronary artery disease, diabetes, proximal LAD occlusion and left ventricular dysfunction ${ }^{[9-12]}$.

In recent decades, hospitals and surgeons have been called upon to present their findings to the medical community and society. The European EuroSCORE study showed general mortality in cardiac surgery around 3.1\%, while the American multicenter Society of Thoracic Surgeons (STS), around $2.0 \%{ }^{[13,14]}$. Hannan et al. ${ }^{[15]}$, analyzing 49,830 patients undergoing CABG surgery in New York state between 2001 and 2004, found mortality around 1.19\%, stroke around 1.2\%, transmural infarction $0.5 \%$ sternal infection $0.9 \%$, reoperation for bleeding $1.9 \%$, sepsis $1.0 \%$, renal dialysis $1.4 \%$, respiratory failure $3.7 \%$, and reoperation $1.2 \%$.

In our country, Silva et al. ${ }^{[16]}$ showed an operative mortality rate of $4.0 \%$ in patients operated by the Unified Health System (SUS) at the Hospital Beneficência Portuguesa in São Paulo, while Fortes et al. ${ }^{[16,17]}$ showed an average mortality of $7.4 \%$ in patients referred for $C A B G$ in a university hospital in northeastern Brazil. TotalCor Hospital, a private hospital focused on cardiology, points to a mortality rate of $1.7 \%$. The profile of the patient operated in this private hospital is also favorable, with an expected mortality rate of $0.7 \%{ }^{[18]}$.

The BYPASS Registry is the first study of a Brazilian multicenter database with national representativity. The records strengthen that Brazilian patients, in general, have little access to primary prevention and surgery was indicated after heart attacks, heart failure and ventricular dysfunction. Brazilian patients have unsatisfactory outpatient follow-up and are generally poorly medicated, either due to poor adherence or lack of medication in the public healthcare system.
Since it is a voluntary participation, currently 17 Brazilian centers spontaneously provide their data to the BYPASS Registry. It should be remembered that the STS database also started with few centers and still does not reach all centers yet, but around 90\%. Over the years, the participation of centers increased due to the benefits of having their results analyzed and receiving advice to improve hospital processes focused on surgical quality and patient safety. Currently, the STS participating center is a recognized center for quality control and continuous improvement. The TotalCor Hospital in São Paulo provides data for the STS since 2011 and has since reached a decrease in the time of mechanical ventilation and hospital stay through the guidelines received ${ }^{[18]}$. Since its first publication in 2018, the BYPASS study has had great adherence of cardiac surgeons, increasing from 945 to 2292 patients undergoing CABG in follow-up. The BYPASS study also seeks to be an evaluator and consultant in the process of improvement in cardiovascular surgery in Brazil.

Diabetes was more prevalent in patients undergoing revascularization in Brazil, when compared to other international registries, such as the SYNTAX (Synergy Between Percutaneous Coronary Intervention With TAXUS and Cardiac Surgery) trial[ ${ }^{[19]}$. FREEDOM (Future Revascularization Evaluation in Patients with Diabetes Mellitus: Optimal Management of Multivessel Disease) trial defined bypass surgery as the standard treatment for diabetic and multivessel patients, mainly directing these patients for surgery.

Less than one-third of the reported patients undergoing revascularization surgery were female. Approximately $12 \%$ of the patients who underwent surgery had previously undergone percutaneous coronary interventions, an issue that deserves further investigation regarding the quality of the revascularization provided to these patients.

The vast majority of patients (84.4\%) were operated in the public healthcare system, which draws attention since approximately $30 \%$ of Brazilians have private health insurance ${ }^{[20]}$. Such information suggests that many patients with access to private health care are operated on public hospitals, or that patients who have access to private health care initially avoid being referred to surgery.

The analysis showed that operative mortality in CABG in Brazil was slightly higher compared to North American and European centers. This finding is remarkable, given the limited budget, resources and infrastructure of the health system, both private and public, as well as operating rooms and intensive care units, both in basic equipment and human resources.

Brazilian surgeons currently prefer to perform on-pump CABG, the technique employed in $87 \%$ of the cases. In this scenario, cardioplegia has been the preferred strategy for myocardial protection (95.2\%). This is an amazing finding in a country that pioneered the development of off-pump coronary surgery. Minimally invasive or robotic revascularization is not routinely performed in Brazil.

Major complications such as death, cerebrovascular accident, and myocardial infarction were similar to those of international studies. Major bleeding requiring reoperation, arrhythmias, kidney failure, infection and heart failure were also similar.

Vasoplegia was uncommon (0.7\%) in this study. It is a wellknown complication in the postoperative period of cardiovascular 
surgery, defined by hemodynamic collapse similar to septic shock, characterized by decreased systemic vascular resistance, increased cardiac index and severe hypotension, despite the use of vasoactive drugs, occurring in the first postoperative hours ${ }^{[21]}$.

The use of sequential anastomoses is a strategy to minimize aortic manipulation, but also to reduce CPB time and aortic cross-clamping.

Bilateral internal thoracic arteries (ITA) were used only in $4.8 \%$ of the patients, a practice more frequent than that reported by the STS database (4.1\%), but fair below the European practice $(10 \%)^{[22,23]}$. Only $16.9 \%$ of the patients had total arterial graft, of which $69 \%$ of the patients received only one ITA graft.

The radial artery was seldom used (1.1\%); and $7.7 \%$ of the patients received only the saphenous vein as a graft. The saphenous vein graft was widely used (84.1\%), similar to Europe (84.4\%) and the United States (95.1\%)(22-24). The time spent for preparation of the grafts can influence surgical teams with high volume to prefer the saphenous vein use instead of harvesting the second internal thoracic artery. Injury of the LITA during the preparation may also induce the surgeon to perform saphenous surgery instead of preparing the RITA.

Only $32.9 \%$ of the patients had their procedures indicated by the Heart Team, being a growing trend and demands of medical guidelines that patients have indication for cardiac procedures discussed and based on scientific evidence. Since the first report, the BYPASS study has seen a large increase in the participation of the Heart Team in the indication of cardiac surgeries ${ }^{[1]}$.

Understanding the differences between the surgical strategy of the Brazilian surgeon and that of other countries, even with regional differences, may guide and suggest improvements in the routines adopted by different centers ${ }^{[25,26]}$.

The experience of international databases shows that its continuous data management brings long-term benefits, optimizing hospital practices and directing preventive policies. The dissemination of the BYPASS Registry and the invitation to surgeons to provide their data have contributed to the growth of the database. The adherence of several Brazilian centers to provide their data to the BYPASS Registry should be encouraged as part of a process of continuous medical improvement and patient safety. Policies should be designed to help fund national registries and stimulate surgeons to provide their data.

\section{CONCLUSION}

The CABG data in Brazil provided by the BYPASS Registry analysis are, so far, the most representative of our national reality and practice. This database constitutes an important reference for indications and comparisons of therapeutic procedures, as well as to propose subsequent models to improve patient safety and the quality of surgical practice in the country.

\section{No financial support.}

\section{No conflict of interest.}

\section{Authors' roles \& responsibilities}

WJG, JAES, Conception and study design; data management; $J A B O, O B$, manuscript redaction or critical review of its content; $A B C, F B J$ final manuscript approval

Other Substantial contributions to the conception or authors design of the work; or the acquisition, analysis, or interpretation of data for the work; final manuscript approval

\section{REFERENCES}

1. Gomes WJ, Moreira RS, Zilli AC, Bettiati LC, Jr., Figueira F, SSP DA, et al. The Brazilian Registry of Adult Patient Undergoing Cardiovascular Surgery, the BYPASS Project: Results of the First 1,722 Patients. Braz J Cardiovasc Surg. 2017;32(2):71-6. doi: 10.21470/1678-9741-2017-0053.

2. Sousa-Uva M, Neumann FJ, Ahlsson A, Alfonso F, Banning AP, Benedetto $U$, et al. 2018 ESC/EACTS Guidelines on myocardial revascularization. Eur J Cardiothorac Surg. 2019;55(1):4-90. doi: 10.1093/ejcts/ezy289.

3. Thygesen K, Alpert JS, Jaffe AS, Chaitman BR, Bax JJ, Morrow DA, et al. Fourth universal definition of myocardial infarction (2018). Eur Heart J. 2019;40(3):237-69. doi: 10.1093/eurheartj/ehy462.

4. Kennedy MW, Kaplan E, Hermanides RS, Fabris E, Hemradj V, Koopmans PC, et al. Clinical outcomes of deferred revascularisation using fractional flow reserve in patients with and without diabetes mellitus. Cardiovasc Diabetol. 2016;15:100. doi: 10.1186/s12933-016-0417-2.

5. Mansur Ade P, Favarato D. Mortality due to cardiovascular diseases in Brazil and in the metropolitan region of São Paulo: a 2011 update. Arq Bras Cardiol. 2012;99(2):755-61. doi: 10.1590/S0066-782X2012005000061.

6. Buffolo E, Andrade JC, Succi JE, Leao LE, Cueva C, Branco JN, et al. Direct myocardial revascularization without extracorporeal circulation: technique and initial results. Tex Heart Inst J. 1985;12(1):33-41.

7. Calafiore AM, Teodori G, Di Giammarco G, Vitolla G, Maddestra N, Paloscia $\mathrm{L}$, et al. Multiple arterial conduits without cardiopulmonary bypass: early angiographic results. Ann Thorac Surg. 1999;67(2):450-6.

8. Kolh P, Windecker S, Alfonso F, Collet JP, Cremer J, FalkV, et al. 2014 ESC/ EACTS Guidelines on myocardial revascularization: the Task Force on Myocardial Revascularization of the European Society of Cardiology (ESC) and the European Association for Cardio-Thoracic Surgery (EACTS). Developed with the special contribution of the European Association of Percutaneous Cardiovascular Interventions (EAPCI). Eur J Cardiothorac Surg. 2014;46(4):517-92. doi: 10.1093/ejcts/ezu366.

9. Hueb W, Lopes N, Gersh BJ, Soares PR, Ribeiro EE, Pereira AC, et al. Tenyear follow-up survival of the Medicine, Angioplasty, or Surgery Study (MASS II): a randomized controlled clinical trial of 3 therapeutic strategies for multivessel coronary artery disease. Circulation. 2010;122(10):949-57. doi: 10.1161/circulationaha.109.911669.

10. Yusuf S, Zucker D, Peduzzi P, Fisher LD, Takaro T, Kennedy JW, et al. Effect of coronary artery bypass graft surgery on survival: overview of 10-year results from randomised trials by the Coronary Artery Bypass Graft Surgery Trialists Collaboration. Lancet.1994;344(8922):563-70

11. Serruys PW, Morice MC, Kappetein AP, Colombo A, Holmes DR, Mack $\mathrm{MJ}$, et al. Percutaneous coronary intervention versus coronary-artery bypass grafting for severe coronary artery disease. N Engl J Med. 2009;360(10):961-72. doi: 10.1056/NEJMoa0804626

12. Kapoor JR, Gienger AL, Ardehali R, Varghese R, Perez MV, Sundaram $V$, et al. Isolated disease of the proximal left anterior descending artery comparing the effectiveness of percutaneous coronary 
interventions and coronary artery bypass surgery. JACC CardiovasC Interv. 2008;1 (5):483-91. doi: 10.1016/j.jcin.2008.07.001.

13. Grant SW, Hickey GL, Dimarakis I, Trivedi U, Bryan A, Treasure T, et al. How does EuroSCORE II perform in UK cardiac surgery; an analysis of 23740 patients from the Society for Cardiothoracic Surgery in Great Britain and Ireland National Database. Heart. 2012;98(21):1568-72. doi:10.1136/heartjnl-2012-302483.

14. Jacobs JP, Shahian DM, Prager RL, Edwards FH, McDonald D, Han JM, et al. Introduction to the STS National Database Series: Outcomes Analysis, Quality Improvement, and Patient Safety. Ann Thorac Surg. 2015;100(6):1992-2000. doi: 10.1016/j.athoracsur.2015.10.060

15. Hannan EL, Wu C, Smith CR, Higgins RS, Carlson RE, Culliford AT, et al. Off-pump versus on-pump coronary artery bypass graft surgery: differences in short-term outcomes and in long-term mortality and need for subsequent revascularization. Circulation. 2007;116(10):114552. doi: 10.1161/circulationaha.106.675595.

16. Silva GSD, Colosimo FC, Sousa AG, Piotto RF, Castilho V. Coronary Artery Bypass Graft Surgery Cost Coverage by the Brazilian Unified Health System (SUS). Braz J Cardiovasc Surg. 2017;32(4):253-9. doi: 10.21470/1678-9741-2016-0069.

17. Fortes JV, Barbosa e Silva MG, BaldezTE, Costa MA, da Silva LN, Pinheiro RS, et al. Mortality Risk After Cardiac Surgery: Application of Inscor in a University Hospital in Brazil's Northeast. Braz J Cardiovasc Surg. 2016;31(5):396-9. doi: 10.5935/1678-9741.20160080.

18. Barros e Silva PG, Baruzzi AC, Ramos DL, Okada MY, Garcia JC, Cardoso $\mathrm{F}$ de $\mathrm{A}$, et al. Improving Indicators in a Brazilian Hospital Through Quality-Improvement Programs Based on STS Database Reports. Braz J Cardiovasc Surg. 2015;30(6):660-3. doi: 10.5935/1678-9741.20150075.

19. Farkouh ME, Domanski M, Sleeper LA, Siami FS, Dangas G, Mack M, et al. Strategies for multivessel revascularization in patients with diabetes.
N Engl J Med. 2012;367(25):2375-84. doi: 10.1056/NEJMoa1211585.

20. Bocchini B. Pesquisa mostra que quase $70 \%$ dos brasileiros não têm plano de saúde particular. Brasília: Empresa Brasil de Comunicação; 2018 [cited 2019 Feb 22]. Available from: http://agenciabrasil.ebc. com.br/geral/noticia/2018-02/pesquisa-mostra-que-quase-70-dosbrasileiros-nao-tem-plano-de-saude-particular.

21. Hossne Junior NA, Miranda M, Monteiro MR, Branco JN, Vargas GF, Pestana JO, et al. Cardiopulmonary bypass increases the risk of vasoplegic syndrome after coronary artery bypass grafting in patients with dialysis-dependent chronic renal failure. Rev Bras Circ Cardiovasc. 2015;30(4):482-8. doi: 10.5935/1678-9741.20140092.

22. Schwann TA, Tatoulis J, Puskas J, Bonnell M, Taggart D, Kurlansky P, et al. Worldwide Trends in Multi-arterial Coronary Artery Bypass Grafting Surgery 2004-2014: A Tale of 2 Continents. Semin Thorac Cardiovasc Surg. 2017;29(3):273-80. doi: 10.1053/j.semtcvs.2017.05.018

23. Deutsch O, Gansera L, Wunderlich M, Eichinger W, Gansera B. Does Bilateral ITA Grafting Increase Perioperative Complications? Outcome of 6,476 Patients with Bilateral versus 5,020 Patients with Single ITA Bypass. Thorac Cardiovasc Surg. 2016;64(3):188-94. doi: 10.1055/s-0035-1558992.

24. ElBardissi AW, Aranki SF, Sheng S, O'Brien SM, Greenberg CC, Gammie JS. Trends in isolated coronary artery bypass grafting: an analysis of the Society of Thoracic Surgeons adult cardiac surgery database. JThorac Cardiovasc Surg. 2012;143(2):273-81. doi: 10.1016/j.jtcvs.2011.10.029.

25. Gomes WJ, Mendonca JT, Braile DM. Cardiovascular surgery outcomes opportunity to rediscuss medical and cardiological care in the Brazilian public health system. Rev Bras Cir Cardiovasc. 2007;22(4):iii-vi. doi: 10.1590/S0102-76382007000400002.

26. Rao C, Zhang H, Gao H, Zhao Y, Yuan X, Hua K, et al. The Chinese Cardiac Surgery Registry: Design and Data Audit. Ann Thorac Surg. 2016;101(4):1514-20. doi: 10.1016/j.athoracsur.2015.09.038. 